\title{
Identification and Phylogenetic Studies of a New Probiotic Lactobacillus spp. Egyptian Isolate Based on 16s rRNA Gene
}

\author{
Ahmed R Awd ${ }^{1}$, Khater A Khater ${ }^{1}$ and Ahmed I Ismail ${ }^{2,3 *}$ \\ ${ }^{1}$ Dairy Science and Technology Department, Faculty of Agricultural, Al-Azhar \\ University, Egypt \\ ${ }^{2}$ Biotechnology Department, Faculty of Agriculture, University of Al-Azhar, Cairo, \\ Egypt \\ ${ }^{3}$ Public Health Department, College of Applied Medical Sciences, Majmaah University, \\ Al-Majmaah, Saudi Arabia \\ *Corresponding Author: Ahmed I Ismail, Biotechnology Department, Faculty of \\ Agriculture, University of Al-Azhar, Cairo, Egypt and Public Health Department, College \\ of Applied Medical Sciences, Majmaah University, Al-Majmaah, Saudi Arabia. \\ DOI: 10.31080/ASNH.2020.04.0654
}

\begin{abstract}
Lactobacillus represents one of the most important genera of human and animal intestinal tract. They are used in dairy and nondairy probiotics foods to restore the intestinal microflora, which provides a health benefit. Lactobacillus strains were phenotypically identified and described using biochemical features and kits such as the API $50 \mathrm{CH}$ system. Conventional biochemical and physiological studies have certain limitations when discriminating against large numbers of isolates with similar physiological characteristics. They are generally unreliable, and consuming money, time, and effort. There are many studies have focused on the rapid identification of molecular biology techniques for the rapid identification and detection of lactobacilli. In this study, we examined five pairs of primers on complex communities to facilitate the examination of complex micro-ecosystems. The two primers Lac1-Lac2 and Joh16SI-Joh16II showed positive results with L. casei, L. rhamnosus, and L. gasseri. Their strains were isolated from raw milk and feces of breast-fed infants. The fragments obtained from DNA samples after PCR amplification were sequenced and submitted in GenBank "NCBI" under accessions number "KY123805", "KY123789" and "KY123806". As the long-term goal of this research was to obtain patent protection for Lactobacillus sp. isolated from Egyptian resources and using it in food and dairy industries.

Keywords: API 50 CH; GenBank; Intestinal Microflora; Lactobacillus; Molecular Identification; Phylogenetic; Probiotics; 16S rRNA
\end{abstract}

\section{Introduction}

Lactobacillus spp. are microorganisms with a long-documented history of use in dairy technology and as a natural preservative in dairy products due to their ability to inhibit the growth of harmful bacteria and thus increasing the shelf life of the products [1]. In addition, The interest is enhanced by proven probiotic properties that give consumers a health benefit [2]. The genus of Lactobacillus is one of the major members of lactic acid bacteria (LAB), gram-positive, catalase-negative, rods shaped, non-spore forming bacteria and produce lactic acid as the main end product during carbohydrate fermentation [3].

The members of this genus have been isolated from different sources, e.g. milk, dairy products, sewage, plants, food products, and animal intestines. Currently, this genus contains more than 180 species [4]. However, there is a large degree of heterogeneity within the members of this genus is challenging [5]

Lactobacillus classification is traditional based on morphological and physiological criteria. These conventional criteria are often time-consuming and sometimes fail to identify the bacterial accu- rately. Recently, the use of biochemical characteristics in addition to Kits likes API 50 CHL system and molecular methods such as polymerase chain reaction (PCR) provided a novel approach for bacterial identification [6].

Therefore, the purpose of the inquiry under way was to isolate and classify some Lactobacillus spp.by classical (morphology and biochemical features included API 50 CHL system) and molecular (PCR technique) methods. An additional aim was to registering patent protection for Lactobacillus spp. Strains are isolated locally from Egyptian resources to increase the additive value of the Egyptian microbial diversity.

\section{Materials and Methods}

Samples collection

Forty-Nine Samples were collected from different healthy mother breast milk, fresh feces of breast-fed infants, raw milk and some dairy products. The infant ages varied from 1 to 8 months. Samples were kept in sterile glass containers, transported within two hours in the icebox to the laboratory and analyzed on the same day. 


\section{Isolation of lactobacilli culture}

Serial dilution of each sample in citrate buffer was plated on MRS agar medium [7], Then incubated at $37^{\circ} \mathrm{C}$ for 48 hours under anaerobic conditions using GENBox anaerobic kit. Obtained colony were randomly picked, streaking twice on MRS agar plates and pre-incubated under the same previous conditions, to ensure complete purification.

\section{Identification of isolated cultures}

About 90 isolates were tested for Gram-staining [8], catalase activity [9], and cell morphology. In order to obtain a complete physiological characterization of the isolates, the following properties were also examined: the formation of acid and $\mathrm{Co}_{2}$ from glucose [10], growth at 15 and $45^{\circ} \mathrm{C}$, fermentation of glucose, indol production and gelatin liquefaction [11].

\section{API 50 CHL system}

API 50 CHL medium, intended to classify the Lactobacillus genus and related genera. This medium allows 49 different carbohydrates to be fermented on the API 50 CHL strip. A suspension is made with the micro-organism to be evaluated in the liquid (API 50 CHL medium), and each strip tube is then inoculated with the suspension. Through incubation, the carbohydrates are fermented into acids that cause a decrease in $\mathrm{pH}$, as indicated by the indicator color change. The results constitute the biochemical profile which the identification software uses to classify the strain.

\section{Molecular biology studies (Wet lab)}

- Genomic DNA isolation and quantification: Seven isolates of total genomic DNA were extracted using (Gene JET Genomic DNA Purification Protocol Kit\#K0721-Thermo Fisher Scientific Inc.) and eight isolates were extracted using. (ZR Fungal/Bacterial DNA MiniPrep ${ }^{\mathrm{TM}}$ Catalog No D6005 -Zymo Research CORP.). The DNA extraction procedure was performed in compliance with manual of the manufacturer. BTotal DNA was visualized on $1 \%$ agarose gel to determine DNA quality. Smeared appearance samples were considered as fragmented DNA and were excluded, DNA concentration was determined using a UV Dual-Intensity Trans Illuminator and quantified using a spectrophotometer (GENWAY630).

- Selection of Primers for Lactobacillus identification: Lactobacillus species and group-specific primers were selected based on the sequences of 16S rRNA [12-14] (Table 1).

- PCR amplification for 16S: Amplification reactions were prepared in total volumes of $50 \mu \mathrm{l}$ containing $25 \mu \mathrm{l}$ GoTaq ( $)$ Promega, a pair of specific primers at a concentration of $0.25 \mu \mathrm{mol}, 2 \mu \mathrm{l}$ Template DNA and water nuclease-free Up to $50 \mu \mathrm{l}$ each primers. PCR amplifications were performed in Eppendorf Master Cycler Gradient using the following PCR temperature profile: denaturation cycle of $94^{\circ} \mathrm{C}$ for $5 \mathrm{~min}$ utes, followed by 35 cycles of $94^{\circ} \mathrm{C}$ for 1 minute, annealing temperature $\left(51^{\circ} \mathrm{C}, 53^{\circ} \mathrm{C}, 55^{\circ} \mathrm{C}, 57^{\circ} \mathrm{C}, 62^{\circ} \mathrm{C}\right.$ and $\left.65^{\circ} \mathrm{C}\right)$ for 1 minute for optimum annealing temperature, DNA extension $72^{\circ} \mathrm{C}$ for $90 \mathrm{~s}$ and final cycle $72^{\circ} \mathrm{C}$ for 5 minutes. and then kept at $4^{\circ} \mathrm{C}$ until further use.

- Amplified fragments visualization: Agarose gel electrophoresis 1.5\% (wt/vol) was used to visualize the amplified DNA fragments, gels were stained with ethidium bromide $(0.5 \mu \mathrm{g} /$ $\mathrm{ml}$ ) and loaded directly onto the gel, DNA ladder was also loaded onto the gel for comparison of fragment size and visualized under UV light (Dual - Intensity Trans Illuminator) and quantified using spectrophotometer (GENWAY630). The PCR product containing DNA fragments with the expected size were purified using GeneJET ${ }^{\mathrm{TM}}$ PCR Purification Kit (Thermo \#K0701), then subjected to sequencing.

- Sequencing of 16S: The species specificity of the primers Fragments of PCR products for Lac1 - Lac2 and Joh16SI-Joh16SII primers were sent to the University of Potsdam, Institute of Biochemistry and Biology, (Potsdam, Germany) for sequencing using an ABI 3730xl DNA sequencer. The nucleotide sequences for resulted fragments were deposited to the Genbank Database in date 14 and 16 Nov 2016 and it has been named as Strain AZ1 using Bankert tool.

Bioinformatics workflow (dry lab)

- Primer selectivity based on in silico studies: Before proceeding to wet laboratory, the in silico have been validated. Each primer's properties including melting temperature, percentage of GC content and suitability for PCR have been described in the report. It helps us assess potential PCR primers from the list of primers selected from Previous research for all the species being studied Lactobacillus sp. $L$. acidophilus, L. johnsonii, L. rhamnosus, L. reuteri. NCBI blast primer tool http://www.ncbi.nlm.nih.gov/tools/primer was used to test the primers as it has a wide range of parameters in this process include, $\mathrm{nr}$ database and Lactobacillus.

- Sequences submissions and accession numbers: The sequences of this study have been submitted to the NCBI using the Bankit tool http://www.ncbi.nlm.nih.gov/BankIt/.

- Sequences analysis: A search was carried out using the online tool NCBI BLASTn http:/ncbi.nlm.nih.gov/BLAST/ against the database for the collection of nucleotides $(\mathrm{nr} /$ nt) to find Sequence Similarity. The default parameters of BLASTN have been used.

- Phylogenetic tree construction: A phylogenetic tree was designed based on the $16 \mathrm{~S}$ ribosomal RNA sequence comparisons of the PCR-amplified length polymorphism and Database sequences using blast tree construct in https:/ www.ncbi.nih.gov/blast/treeview based on Fast Minimum Evolution. 


\begin{tabular}{|c|c|c|c|c|c|c|}
\hline Species & Primer & Nucleotide sequence & ${ }^{*} \mathbf{A T}\left(\mathbf{C}^{\circ}\right)$ & $\begin{array}{c}\text { PCR } \\
\text { product(bp) }\end{array}$ & $\begin{array}{c}\text { Target } \\
\text { Sequence }\end{array}$ & References \\
\hline Lactobacillus sp. & $\begin{array}{l}\text { Lac1 } \\
\text { Lac2 }\end{array}$ & $\begin{array}{l}\text { F AGAGTTTGATCCTGGCTCAG } \\
\text { R GGTTACCTTGTTACGACTT }\end{array}$ & 58 & 1523 & 16S rDNA & (McOrist., et al. 2002) \\
\hline L. acidophilus & $\begin{array}{l}\text { Aci I } \\
\text { Aci II }\end{array}$ & $\begin{array}{l}\text { F AGCTGAACCAACAGATTCAC } \\
\text { R ACTACCAGGGTATCTAATCC }\end{array}$ & 62 & 785 & 16S rDNA & (Walter., et al. 2001) \\
\hline L. johnsonii & $\begin{array}{l}\text { Joh } 16 \text { SI } \\
\text { Joh } 16 \text { SII }\end{array}$ & $\begin{array}{l}\text { F GAGCTTGCCTAGATGATTTTA } \\
\text { R ACTACCAGGGTATCTAATCC }\end{array}$ & 57 & 760 & 16S rDNA & (Walter., et al. 2001) \\
\hline L. rhamnosus & $\begin{array}{l}\text { Rhal } \\
\text { Rhall }\end{array}$ & $\begin{array}{l}\text { F CAGACTGAAAGTCTGACGG } \\
\text { R GCGATGCGAATTTCTATTATT }\end{array}$ & 55 & 399 & 16S rDNA & $\begin{array}{l}\text { (Tilsala-Timisjarvi., et al. } \\
\text { 1997) }\end{array}$ \\
\hline L. reuteri & $\begin{array}{l}\text { ReuI } \\
\text { ReuII }\end{array}$ & $\begin{array}{l}\text { F GCCGCCTAAGGTGGGACAGAT } \\
\text { R AACACTCAAGGATTGTCTGA }\end{array}$ & 55 & 483 & 16S rDNA & (Walter., et al. 2001) \\
\hline
\end{tabular}

Table 1: The five the primer sets which used in the study.

*AT(Co): Annealing Temperature.

\section{Results and Discussion}

Phenotypic identification of bacterial isolates

Like many other bacterial species, Lactobacillus strains have been phenotypically identified with the use of biochemical characteristics and kits such as API $50 \mathrm{CH}$ system. As shown in (Table 2), the obtained data declared that 39 out of 90 isolates were rods, gram-positive and catalase-negative strains. On the other hand, four isolates from human milk samples were able to liquefy gelatin and produce $\mathrm{Co}_{2}$ during glucose fermentation. Moreover, all isolates from faecal and raw milk samples were also able to produce acid and gas through the fermentation of glucose. In contrast, only five isolates were failed to fermentation glucose. Thus, all these isolates were completely excluded.
Continuously, in this study, four Lactobacillus strains were identified with the use of the API $50 \mathrm{CHL}$ system as belonging to L. rhamnosus and L. casei from infantile faecal samples. In this connection, similar groups of Lactobacillus strains had been earlier isolated from infantile faecal specimens from other countries $[15,16]$, although slight variations could be observed.

In addition, this investigation was also identified by the API 50 CHL system. Also, from the present data, it was of interest to notice that 3 out of 4 tested strains identified by API 50 CHL system were isolated from infantile faecal specimens, while only one strain from raw milk samples, in contrast, no strain from colostrum can be identified by API 50 CHL system. However, the same observation

\begin{tabular}{|l|c|c|c|c|c|c|c|c|c|}
\hline \multirow{2}{*}{ Samples } & \multirow{2}{*}{ No. of isolates } & \multicolumn{2}{c|}{ Morphology } & \multicolumn{2}{c|}{ Gram staining } & Catalase production & \multirow{2}{*}{$\begin{array}{c}\text { Gelatin } \\
\text { Liquefied }\end{array}$} & $\begin{array}{c}\text { Indole } \\
\text { Produced }\end{array}$ \\
\cline { 3 - 10 } & & Rods & Cocci & + & - & + & - & +4 & - \\
\hline Human milk (H) & 22 & 16 & 6 & 22 & - & 2 & 14 & -10 & - \\
\hline Faeces (F) & 36 & 18 & 2 & 20 & 16 & 2 & 16 & - & - \\
\hline Raw Milk (RM) & 20 & 5 & 3 & 8 & 12 & 1 & 4 & - & - \\
\hline Rayeb milk (Ray) & 3 & 2 & 1 & 3 & - & - & 2 & - & - \\
\hline Yoghurt (Y) & 2 & 1 & 1 & 2 & - & - & 1 & - & - \\
\hline Karish cheese (k) & 7 & 5 & - & 5 & 2 & 3 & 2 & - & - \\
\hline Total & 90 & 47 & 13 & 60 & 30 & 8 & 39 & 35 & 35 \\
\hline
\end{tabular}

Table 2: The morphological and biochemical tests used for identification of some isolates.

$$
\text { +: Positive reaction; -: Negative Reaction. }
$$

was previously mentioned by Ozgun and Vural (2011), they concluded that the higher isolation rate of Lactobacillus spp. In infantile faecal specimens than in colostrum may be due to the sterility of colostrum. The isolated Lactobacillus were identified by API 50 CHL system as L. rhamnosus (11.8\%) in addition to other species, from faeces in (Figure 1, 2 and 3).

\section{Molecular studies}

- Amplification of 16S rRNA and visualization: Results of PCR using 16S rRNA specific primers (Lac1- Lac2) amplified two fragment $1251 \mathrm{bp}$, and $1276 \mathrm{bp}$ isolated from feces L. casei in lan1, L. rhamnosus in lan2 and primer (Joh16SIJoh16SII) amplified fragment 729 bp isolated from raw milk L. gasseri in lan3 (Figure 4) and this result agrees with Ven- 


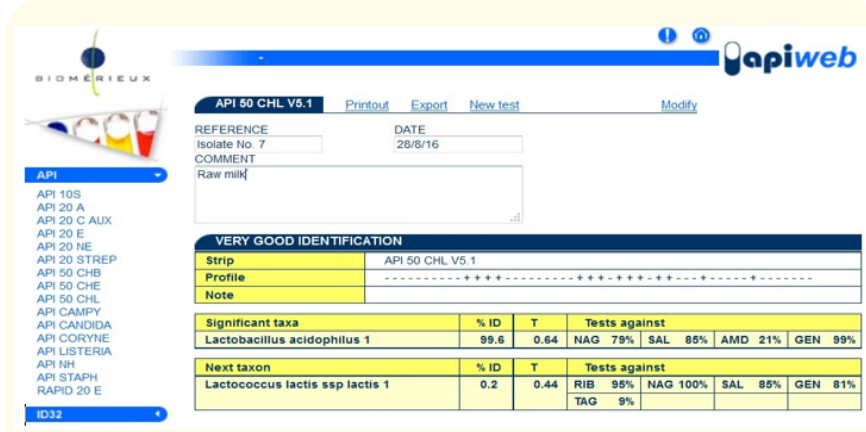

Figure 1: Identification of L. acidophilus 1 by API 50 CHL system.

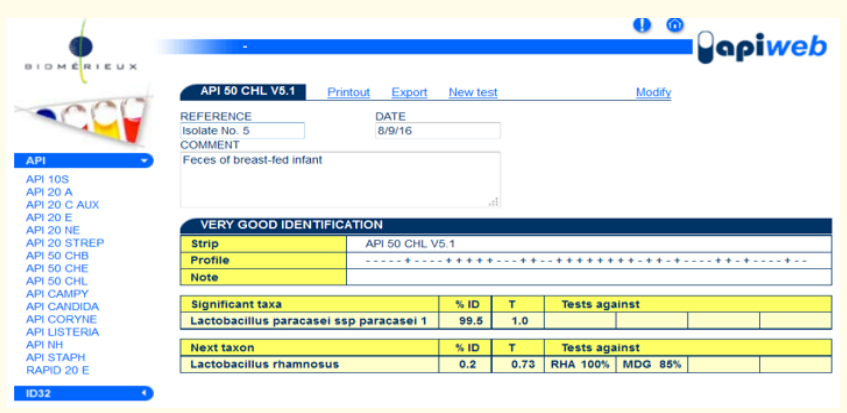

Figure 2: Identification of Lactobacillus paracasei spp paracasei 1 by API 50 CHL system.

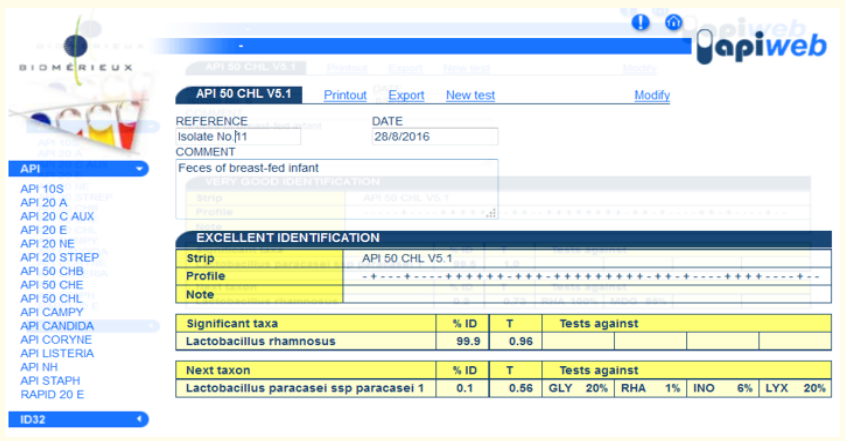

Figure 3: Identification of L. rhamnosus by API 50 CHL system.

tura., et al. (2001). The $16 \mathrm{~S}$ rRNA PCR amplification was thus a useful tool for bacterial species-specific typing due to the considerable variability in size and sequence between organisms.

- Sensitivity and Specificity of the primers: In silico results should be validated before proceeding in the wet lab. PCR Primer Stats receives a list of PCR primers and proceeds a report describing the characteristics of each primer, including melting temperature, percentage of GC content, and PCR suitability. It helped us evaluating the potential of the PCR primers from the list of primers selected by Walter., et al. (2001), McOrist., et al. (2002), and Tilsala and Alatossava (1997) [17] as shown in (Table 3).

- After checking the specificity and efficiency of a primer, thereafter, it is validated in the wet lab. In our study, five pairs of species-specific primers were used the results showed that four primers (Aci I- Aci II) (Joh16SI- Joh16SII) (RhaI- RhaII) (ReuI- ReuII) exhibited the Sensitivity and Specificity of primers for those strains L. acidophilus, L. johnsonii, L. rhamnosus, and L. reuteri. While (Lac-1- Lac-2) primer exhibited a lot of strains (Table 4).

- Gene Bank submissions and accession numbers: This is the first study detailing the discovery of L. casei, L. rhamnosus, and L. gasseri from various locations in Egypt applying molecular identification from feces and raw milk analysis and followed by being sequenced and submitted to the NCBI Genbank Database with three new accession numbers (Table 5).

- We have found this strain from feces of a breastfed infant under accession numbers (123805), (123789) under name AZ1 and strain isolated from raw milk under accession (123806) under name AZ1. This confirms that L. casei, L. rhamnosus, and L. gasseri have an excellent ability to survive passage through the gastrointestinal tract in line with the results showed in suggesting that this strain has a superior ecological fitness for adaptation in various hosts and possibly different ecological niches [18]. We found that $16 \mathrm{~S}$ rRNA sequences permitted the biodiversity assessment of populations of Lactobacillus present in human intestinal and raw milk samples. The 16S rRNA sequence offers insights into the exact identification and distribution of Lactobacillus isolates, inter-subject variation and variations between two intestinal regions of the same person in different human subjects.

- Our results showed significant similarity between16S rRNA sequences of different Lactobacillus spp. Present in the Gene Bank database. BLASTn search of the non-redundant Gen Bank database yielded 100 hits for sequences similar to the strains (KY123805, KY123789 and KY123806), results showed the relatively high similarity percentage of $100 \%$ with Lactobacillus rhamnosus strain LRB, complete genome CP016823.1 and Lactobacillus gasseri strain IMAUFB062 16S ribosomal RNA gene, partial sequence JQ805680.1, 99\% similarity with Lactobacillus casei ATCC 393 DNA, complete genome JQ805680.1 (Table 6).

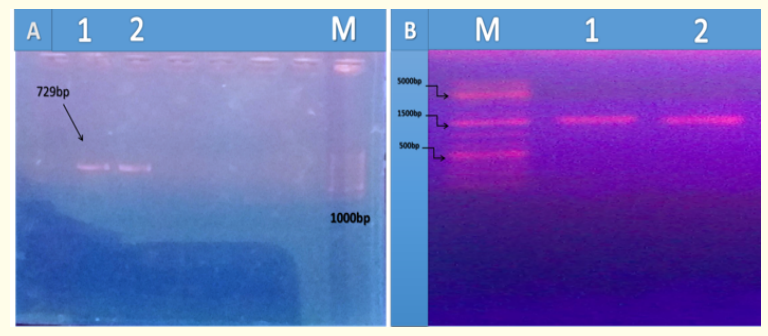

Figure 4: PCR amplified fragments using $16 \mathrm{~S}$ for (A). L. gasseri in a $1 \%$ agarose gel Lanes1-2 ( $\mathrm{M}=1 \mathrm{~kb}$ DNA ladder $)$ primer (Joh16SI-Joh16SII) amplified fragment 729 bp from raw milk. (B) L. casei lane 1 and L. rhamnosus lane 2( $\mathrm{M}=5 \mathrm{~kb}$ DNA ladder) Lanes 1-2 Primer (Lac1 -Lac2): amplified fragment $1251 \mathrm{bp}$ lane 1 and

Lane2 primer: amplified fragment $1276 \mathrm{bp}$ from feces. 


\begin{tabular}{|l|c|c|c|c|c|c|c|}
\hline Primers & Nucleotide sequence & Length NT & GC\% & TM & AT & Product length & Speaces \\
\hline Lac1 & F AGAGTTTGATCCTGGCTCAG & 20 & 50.00 & 56.92 & 58 & 1523 & Lactobacillus sp. \\
\hline Lac2 & R GGTTACCTTGTTACGACTT & 19 & 42.11 & 52.20 & & & \\
\hline Aci I & F AGCTGAACCAACAGATTCAC & 20 & 45.00 & 55.96 & 62 & 785 & L. acidophilus \\
\hline Joh 16SI & R ACTACCAGGGTATCTAATCC & 20 & 45.00 & 52.57 & & & \\
Joh 16SII & F GAGCTTGCCTAGATGATTTTA & 21 & 38.10 & 53.40 & 57 & 760 & L.johnsonii \\
\hline RhaI & F CAGACTACCAGGGTATCTAATCC & 20 & 45.00 & 52.57 & & & L. rhamnosus \\
RhaII & R GCGATGCGAATTTCTATTATT & 21 & 33.33 & 52.89 & & & L. reuteri \\
\hline ReuI & F GCCGCCTAAGGTGGGACAGAT & 21 & 61.90 & 64.26 & 55 & 483 & \\
ReuII & R AACACTCAAGGATTGTCTGA & 20 & 40.00 & 54.20 & & & 559 \\
\hline
\end{tabular}

Table 3: In silico analysis of selection primer sets.

AT: Annealing Temperature; MT: Malting Temperature; GC: Guanine and Cytosine Ratio.

\begin{tabular}{|l|c|c|}
\hline \multicolumn{1}{|c|}{ Primer } & Nucleotide sequence & Strains Lactobacillus spp. \\
\hline Lac1 & F AGAGTTTGATCCTGGCTCAG & L. casei \\
Lac2 & R GGTTACCTTGTTACGACTT & L. rhamnosus \\
\hline
\end{tabular}

Table 4: In silico analysis of selection primer Lac1- Lac2.

\begin{tabular}{|l|c|c|c|c|c|c|c|}
\hline No & Source & Released Data & Locus & Length & Strain & Reference strain & Accession No \\
\hline 1 & Feces of breast-fed infant & $22-\mathrm{NOV}-2016$ & $16 \mathrm{~S}$ rRNA & $1251 \mathrm{bp}$ & AZ1 & Lactobacillus casei & KY123805 \\
\hline 2 & Feces of breast-fed infant & $15-\mathrm{NOV}-2016$ & $16 \mathrm{~S}$ rRNA & $1276 \mathrm{bp}$ & AZ1 & Lactobacillus rhamnosus & KY123789 \\
\hline 3 & Raw milk" from Egyptian cows & $22-\mathrm{NOV}-2016$ & $16 \mathrm{~S}$ rRNA & $729 \mathrm{bp}$ & AZ1 & Lactobacillus gasseri & KY123806 \\
\hline
\end{tabular}

Table 5: Sequence features and accession numbers.

\begin{tabular}{|l|c|c|c|c|c|c|c|}
\hline S. No & Genbank Access NO. & Species of Lactobacillus & Max score & Total score & Query cover & E value & Identity \\
\hline 1 & KY123805 & $\begin{array}{c}\text { Lactobacillus casei strain AZ1 } \\
\text { 16S ribosomal RNA gene, partial } \\
\text { sequence }\end{array}$ & 2311 & 2311 & $100 \%$ & 0.0 & $100 \%$ \\
\hline 2 & KY123789 & $\begin{array}{c}\text { Lactobacillus rhamnosus strain AZ1 } \\
16 \text { S ribosomal RNA gene, partial } \\
\text { sequence }\end{array}$ & 2357 & 2357 & $100 \%$ & 0.0 & $100 \%$ \\
\hline 3 & KY123806 & $\begin{array}{c}\text { Lactobacillus gasseri strain AZ1 } \\
\text { 16S ribosomal RNA gene, partial } \\
\text { sequence }\end{array}$ & 1347 & 1347 & $100 \%$ & 0.0 & $100 \%$ \\
\hline 4 & AP012544.1 & $\begin{array}{c}\text { Lactobacillus casei ATCC 393 DNA, } \\
\text { complete genome }\end{array}$ & 2294 & 11415 & $100 \%$ & 0.0 & $99 \%$ \\
\hline 5 & CP016823.1 & $\begin{array}{c}\text { Lactobacillus rhamnosus strain LRB, } \\
\text { complete genome }\end{array}$ & 2357 & 2357 & $100 \%$ & 0.0 & $100 \%$ \\
\hline 6 & JQ805680.1 & $\begin{array}{c}\text { Lactobacillus gasseri strain } \\
\text { IMAUFB062 16S ribosomal RNA } \\
\text { gene, partial sequence }\end{array}$ & 1347 & 1347 & $100 \%$ & 0.0 & $100 \%$ \\
\hline
\end{tabular}

Table 6: Percentages of similarity of Lactobacillus casei AZ1, rhamnosus AZ1 and gasseri AZ1 and other Lactobacillus spp. as extracted from the Databases using BLASTn.

Phylogenetic relationship of the Genus Lactobacillus spp.

The diversity of Lactobacillus is reflected in the considerable phenotypic and genotypic variation in genus in addition to its ecological versatility. 16S/23S rRNA gene sequence comparative analysis showed phylogenetic relations between the lactobacilli.
Collins., et al. (1991) originally distinguished three phylogenetic groups, the Lactobacillus delbrueckii, Lactobacillus casei-Pediococcus, and Leuconostoc group. Later, he L. casei-Pediococcus group was divided into the Lactobacillus buchneri group, the Lactobacillus reuteri group, the L. casei group, the Lactobacillus Plantarum group, 
and the Lactobacillus salivarius group as well as the L. delbrueckii group was given a new name as the Lactobacillus acidophilus group [19]. Currently, the Lactobacillus genus phylogenetic structure includes the Lactobacillus vitulinus-catenaformis group, Lactobacillus perolens group, and the Pediococcus group [20]. Our data show that 16S-rRNA sequences enable scientists to identify the relations between closely related species. In most cases, Phylogenetic evidence shows that the strains of the same species are closer than those of other species. We have indicated that the divergence rates of (16S-rRNA) sequences can distinguish among subspecies of the same species (Figure 5, 6, and 7).

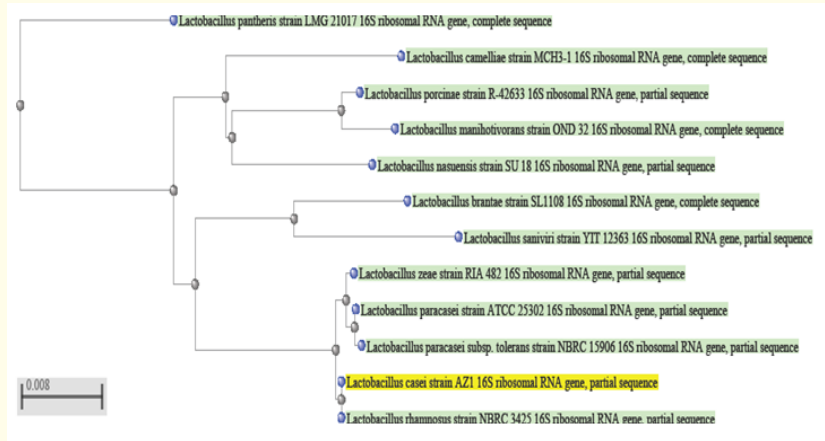

Figure 5: Phylogenetic based on $16 \mathrm{~S}$ ribosomal RNA sequences, shown the inter and intraspecifi relationships of members of Lactobacillus casei strain AZ1.

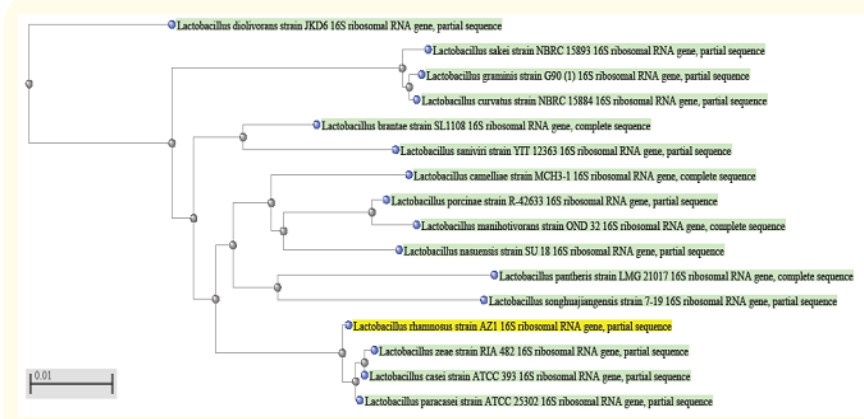

Figure 6: Phylogenetic based on 16S ribosomal RNA sequences, shown the inter and intraspecific relationships of members of Lactobacillus rhamnosus strain AZ1.

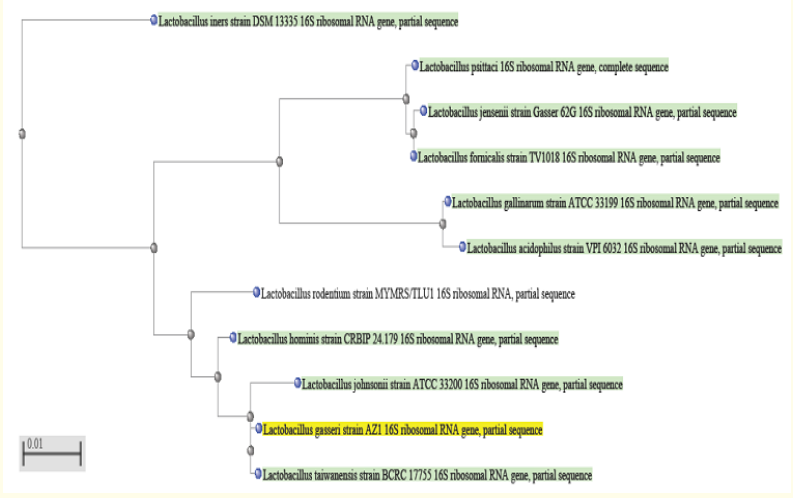

Figure 7: Phylogenetic based on 16S ribosomal RNA sequences, shown the inter and intraspecific relationships of members of Lactobacillus gasseri strain AZ1.

\section{Conclusion}

The Lactobacillus casei group comprises 3 species. This group is homogeneous because it has facultative also heterofermentative members, their GC percentages ranges from 45 to $47 \mathrm{~mol} \%$ and the taking place peptidoglycan type is Lys-d-Asp. Furthermore, All of them are able to form L (+)-lactic acid and to produce acetoin.

The L. casei group includes the most recognized species of Lactobacillus rhamnosus, Lactobacillus paracasei, L. casei, and Lactobacillus zeae. In the past, this subgroup has undergone a broad taxonomic review leading to the temporary rejection of the species name L. Parachuting. Such species are currently still classified in their genus as separate species [21-24]. The most common foodborne lactobacilli isolates of the L. casei group are L. paracasei and L. rhamnosus, especially from cheese. The L. paracasei and L. casei are also present in silage and common in the gastrointestinal tract in animals and humans.

In the L. acidophilus group, homofermentative lactobacilli are almost exclusive. In addition to L. acidophilus, several other species of industrial importance such as L. delbrueckii, Lactobacillus crispatus, with the subspecies bulgaricus, lactis, delbrueckii, and indicus, Lactobacillus helveticus, Lactobacillus johnsonii, and Lactobacillus gasseri are included. L. delbrueckii and L. helveticus perform a recognized role as starters in vegetable and dairy fermentation, respectively, although some strains of the species L. Acidophilus, through their positive effect on intestinal flora, has long been known to play a major role in human health and nutrition.

\section{Acknowledgment}

The author would like to thank the Faculty of Agriculture (Cairo) at Al-Azhar University for supporting this work. Also, the author would like to thank Deanship of Scientific Research at Majmaah University for supporting this work.

\section{Conflict of Interest}

All the authors certify that they have NO affiliations with or involvement in any organization or entity with any financial interest (such as honoraria; educational grants; participation in speakers' bureaus; membership, employment, consultancies, stock ownership, or other equity interest; and expert testimony or patent-licensing arrangements), or non-financial interest (such as personal or professional relationships, affiliations, knowledge or beliefs) in the subject matter or materials discussed in this manuscript.

\section{Bibliography}

1. Anas M., et al. "Antimicrobial activity of Lactobacillus species isolated from Algerian raw goat's milk against Staphylococcus aureus". World Journal of Dairy and Food Sciences 3.2 (2008): 39-49.'

2. Bernardeau M., et al. "Safety assessment of dairy microorganisms: The Lactobacillus genus". International Journal of Food Microbiology 126.3 (2008): 278-285. 
3. Felis GE., et al. "Taxonomy of lactobacilli and bifidobacteria". Current Issues in Intestinal Microbiology 8.2 (2007): 44?.

4. Shintaro M., et al. "Genomic characterization of a fructophilic bee symbiont Lactobacillus kunkeei reveals its niche-specific adaptation". Systematic and Applied Microbiology 39.8 (2016): 516-526.

5. Klein G., et al. "Taxonomy and physiology of probiotic lactic acid bacteria". International Journal of Food Microbiology 41.2 (1998): 103-125.

6. Awaad AM., et al. "Identification of Bifidobacterium Animalis Ssp. Lactis from Egyptian Women Breast Milk and Feces of Breast Fed Infant Based On 16S-23S rRNA Gene". Advances in Nutrition and Food Science 1.1 (2016): 1-8.

7. DE Man C., et al. "A medium for the cultivation of lactobacilli". Journal of Applied Bacteriology 22 (1960): 130-136.

8. Brock TD., et al. "Cell Biology”. In Biology of Microorganisms. Prentice Hall Int. Editions. Toronto, Canada: (1994): 43.

9. Herrero M., et al. "Evaluation of technologically important traits in lactic acid bacteria isolated from spontaneous fermentations". Journal of Applied Bacteriology 81.5 (1996): 565570.

10. Bergey's Manual of Determinative Bacteriology. Ninth Edition. 428 East Preston street Baltimore, Maryland 21202, U.S.A.: Williams and Wilkins; (1994).

11. Collins CH., et al. "Collins and Lyne's microbiological methods". Butterworth and Co Ltd; (2004).

12. Walter J., et al. "Detection and Identification of Gastrointestinal Lactobacillus Species by Using Denaturing Gradient Gel Electrophoresis and Species-Specific PCR Primers". Applied and Environmental Microbiology 66.1 (2000): 297-303.'

13. McOrist AL., et al. "A comparison of five methods for extraction of bacterial DNA from human faecal samples". Journal of Microbiological Methods 50.2 (2002): 131-139.

14. Tilsala-Timisjärvi A., et al. "Development of oligonucleotide primers from the 16S-23S rRNA intergenic sequences for identifying different dairy and probiotic lactic acid bacteria by PCR". International journal of Food Microbiology 35.1 (1997): 49-56.

15. Ogunshe AA. "Bioinihibition of diarrhogenic Gram-positive bacteria pathogens indigenous probiotics in industrial infant weaning food". Asian Pacific Journal of Tropical Medicine 1.2 (2008): 7-11.

16. Ozgun D., et al. "Identification of Lactobacillus strains isolated from faecal specimens of babies and human milk colostrum by API 50 CHL system". Journal of Medical Genetics 3.3 (2011): 46-49.
17. Ventura M., et al. "Specific identification and targeted characterization of Bifidobacterium lactis from different environmental isolates by a combined multiplex- PCR approach". Applied and Environmental Microbiology 67 (2001): 2760-2765.

18. Haschke F., et al. "Clinical trials prove the safety and efficacy of the probiotic strain Bifidobacterium Bb12 in follow-up formula and growing-up milk". MonatsschrKinderheikd 146(1998): 26-30.

19. Schleifer KH., et al. "Phylogeny of the genus Lactobacillus and related genera". Systematic and Applied Microbiology 18.4 (1995): 461-467.

20. Pot B and Tsakalidou E. "Taxonomy and metabolism of Lactobacillus". In: Ljungh, A., Wadstro"m, T. (Eds.), Lactobacillus Molecular Biology: From Genomics to Probiotics. Caister Academic Press, Norfolk, (2009): 3-58.

21. Dellaglio F., et al. "The status of the species Lactobacillus casei"(Orla-Jensen 1916) Hansen and Lessel (1971) and "Lactobacillus paracasei Collins" et al. (1989): request for an opinion". International Journal of Systematic Bacteriology 52, $285 \mathrm{e} 287$.

22. Desai AR., et al. "Discrimination of dairy industry isolates of the Lactobacillus casei group". Journal of Dairy Science 89 (2006):3345-3351.

23. De Vos P., et al. "Judicial commission of the international committee on systematics of prokaryotes, 10th international congress of bacteriology and applied microbiology, minutes of meetings 28, 29 and 31 July and 1 August 2002, Paris, France". International Journal of Systematic and Evolutionary Microbiology 55 (2005): 525e532.

24. Pot B., et al. "Taxonomy of Lactic Acid Bacteria". In: De Vuyst L., Vandamme E.J. (eds) Bacteriocins of Lactic Acid Bacteria. Springer, Boston, MA (1994).

\section{Assets from publication with us}

- Prompt Acknowledgement after receiving the article

- Thorough Double blinded peer review

- Rapid Publication

- Issue of Publication Certificate

- High visibility of your Published work

Website: https://www.actascientific.com/

Submit Article: https://www.actascientific.com/submission.php Email us: editor@actascientific.com

Contact us: +919182824667 